\title{
A review on thermophysical evaluation of alkali-activated geopolymers
}

\begin{abstract}
Recent progress in research on the key thermal expansion properties of amorphous, silicabased, alkali-activated geopolymers and their potential applications are here reviewed and addressed. Besides having great potential as thermal insulators and fire resistant materials since they are not combustible, geopolymers can be applied as interior aircraft components to improve fire resistance, and as coatings for insulator applications and many other potential applications. The raw materials used to make geopolymers are alumino silicates such as fly ash, granulated blast furnace slag, and calcined kaolinite clays. The raw materials can be obtained from biomass waste such as rice husk ash, palm oil ash, and rice husk bark ash. Different raw materials will exhibit different thermal expansion/shrinkage due to their different chemical compositions. In addition, processing of geopolymer material will result in diverse thermal properties due to the different molarity of the alkaline activated solutions used and method of preparation. Interestingly, it was found that the dilatometer curve is influenced by many factors such as aluminosilicate source, silica to alumina ratio, geopolymer mixing ratio, chemical composition and type of geopolymer-such as composite, coating or hybrid. These characteristics are investigated further in this review paper.
\end{abstract}

Keyword: C. Thermal expansion; Geopolymer; Alumino silicate; Energy; Insulation 